\title{
The Basilica of Santa Maria di Collemaggio in L'Aquila: Modern Provisional Measures
}

\author{
Sabatino Cecchini and Francesca Curotti \\ Department of Architectural Technologies and Design (TAED), University of Architecture, Florence 50125, Italy
}

\begin{abstract}
The case in analysis is Santa Maria di Collemaggio, the church symbol of the town of L'Aquila and the most important example of Romanesque style in Abruzzi, tragically damaged by the earthquake in 2009. The following paper starts with an accurate analysis of the Basilica, whose historical, stylistical cultural characteristics make it an unicum in the whole urban environment. The authors tried to identify in which way these values have been compromised or altered after the earthquake through several analysis (surveys, historical researches etc.) aiming at the recognition of collapses, the cracks profile, the structural transformations caused by the provisional measures: the goal is to provide a kind of Basilica "cognitive manual” that will be useful for the future interventions. This first analysis allowed to understand many aspects: on the one hand, the constructive phases and which damages were caused by past careless interventions of restoration, drawing attention to the vulnerability elements of the Basilica; on the other hand, the innovative technologies and materials of the post-seismic provisional measures and their exact location.
\end{abstract}

Key words: Earthquake L’Aquila 2009, Santa Maria di Collemaggio, damages, provisional measures, abacus of measures.

\section{Introduction}

On April 6th, 2009, at 3:33 a.m., the town of L'Aquila (central Italy) was hurt by a severe earthquake.

The phenomenon took the features of a catastrophe at the urban scale: its physical properties, such as intensity (measured 5.9 on the Richter scale), duration (almost $30 \mathrm{~s}$ ), location of hypocentre and epicentre (respectively $10 \mathrm{~km}$ of depth in the crust and $1.5 \mathrm{~km}$ from the town centre) combined with a very high masonry buildings vulnerability and a lacking policy of seismic prevention, caused the total or partial destruction of more than 10,000 buildings and more than 300 victims only in L'Aquila [1].

At once the centre of the town was evacuated and a huge number of refugee camps were made to take in about 65,000 homeless people, one of the widest, took place not so far from the "red zone" of the inner city, exactly in the square of the great Basilica of Santa Maria di Collemaggio.

Also a widespread activity of safety measures were

Corresponding author: Sabatino Cecchini, architect, research fields: architecture and restoration. E-mail: sabatino_87@libero.it. taken for the preservation of the buildings, in order to a future and more careful restoration. Immediately after the rescue of people, hundreds of teams of firefighters provided for the propping of one of the biggest old town centre in Italy, a procedure lasted many months and cost about 200 million Euro.

The following study is dealing with the Basilica of Santa Maria di Collemaggio, one of the most precious monuments of L'Aquila. It starts from the wish to contribute to the knowledge of an architectural good in order to give the unavoidable basis for effective restoration measures.

The seism is always a tragic event, but also an opportunity able to light up the critical aspects of the buildings and to reveal all these interventions of the past, which did not always respect its characteristics and peculiarities.

In this aspect, the Basilica is a shining example.

For a real comprehension of its organism, it was necessary in primis to "decompose" the architectural good in his complex "values-system", consisting in its historical-executive, aesthetical-perceptual and socio-cultural features. 
If one considers the particular conditions of the Basilica in this moment, these studies should be integrated with an additional analysis of the damage conditions and of the temporary measures adopted until now.

In this way, it has been possible to sketch a framework in which recompose the pieces of a puzzle that is the building, in order to do the groundwork for restoration measures oriented not only to the good but also to its "memory", an element that participates with the other ones to identify it like an "unicum".

\section{Urban Setting, Placement and Social Value}

The Basilica of Santa Maria di Collemaggio is considered not only the symbol-church of L'Aquila, but also of the whole its region: Abruzzi.
A planimetric view of the town shows that the most important buildings are placed inside the urban fabric, the still desolate "red zone" of today, instead, the Basilica is clearly defiladed out of the town's limits and is linked with it through two different paths: the oldest one (identified on the Fig. 1 by means of a red broken line) is the original connection, the only existing until 19th century, when the second one were opened (the red uninterrupted line on the Fig. 1). This one allows to reach easily the Basilica from Piazza del Mercato, the principal square of L'Aquila, where the dome of S. Massimo and S. Giorgio and the market are located. In front of the Basilica, the path widens into a rectangular, deep grassland that dates back to the Napoleonic Age.

Despite her position, the Basilica has an essential

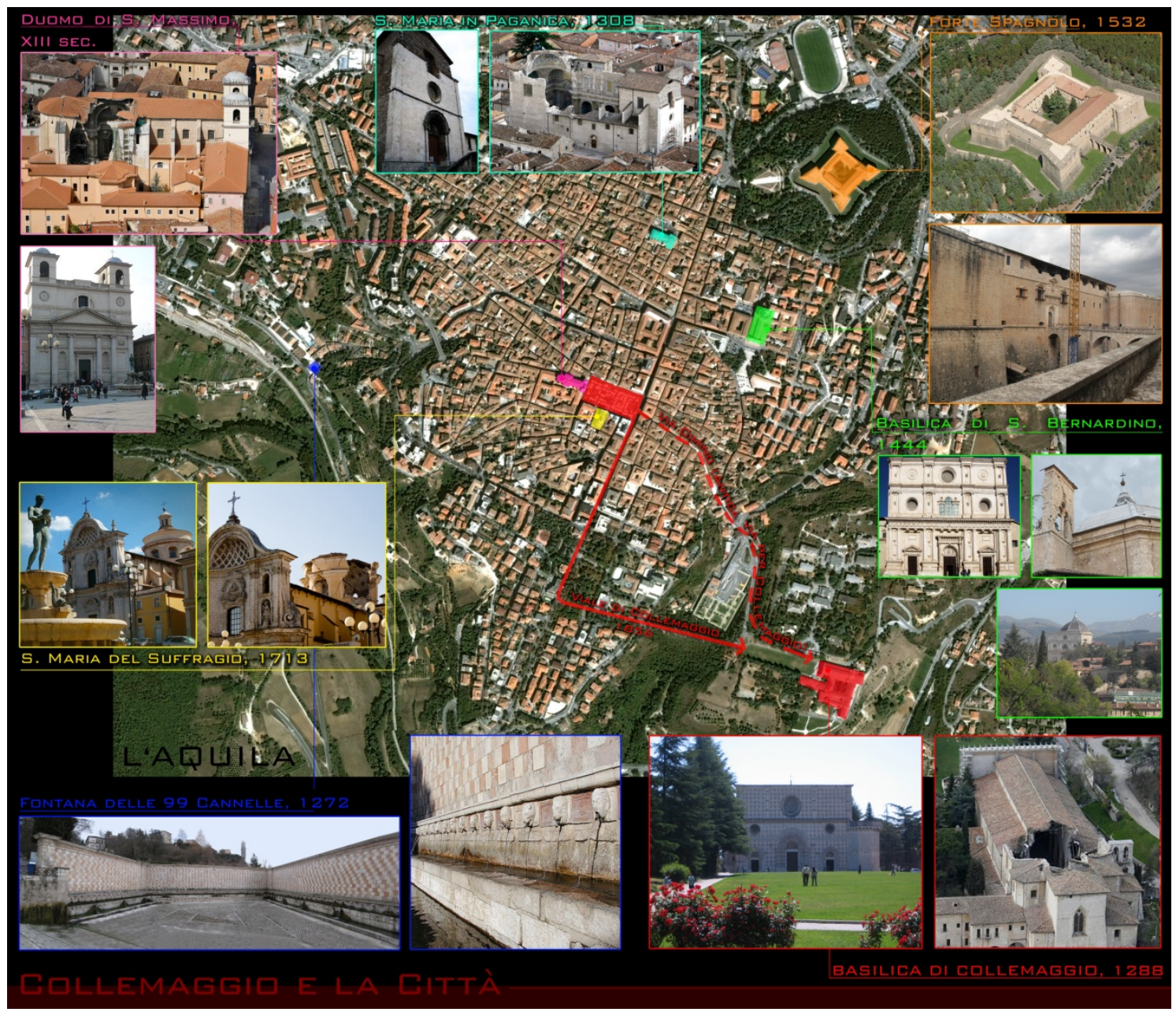

Fig. 1 The double paths to connect the town to the Basilica. 
social role from time immemorial: it is the heart of the Perdonanze celebration, reminding the opening of the first Holy Door of Christendom (Fig. 2). This historical-religious event takes place in the city since 1294, during the last week of August, when the hermit friar Pietro del Morrone was crowned pope with the name of Celestino the Fifth in the Basilica. In fact, the name "Perdonanza" comes from the "Bolla del Perdono", a plenary indulgence granted to whoever visited the church during the vespers on the 28th and 29th August of each year. In memory of this, during the Perdonanza's week, in L'Aquila, there are many manifestations among which the most important is the procession ending exactly outside the Holy Door.

Thanks to the strong identity value characterizing this sacred place, people still live it, in spite of the seism, and continue to identify themselves with it: S. Maria di Collemaggio was the first and the only religious building keeping on its functions in the immediate post-seism.

\section{History: The Five Constructive Phases}

The church's history is very complex, so the authors have decided to summarize it identifying five main historical phases, considering the major earthquakes came in succession during the history of the fabric (Figs. 3 and 4) [2].

(1) 1st phase, 1287-1349: the early Basilica.

An analysis of the masonry-works reveals that the church was born as a roman fortress (castrum). Near here, in 1287, Pietro "the hermit" had the Virgin Mary's apparition and, become pope, decided to raise a Basilica using the Roman pre-existences.

1349: X degree of the Mercalli scale.

(2) 2nd phase, 1349-1461: Radical reconstruction.

From this moment, the building's history is marked by many, violent earthquakes, that caused tangible changes in the plan. After the first one, a new chorus was built at the east end of the fabric, the Holy Door was opened (1397) and the covering of the façade begun (1440).

1461: XI degree of the Mercalli scale.

(3) 3rd phase, 1461-1703: Renaissance and Baroque ages.

New breakdowns and rebuildings characterized the 16, 17 and 18 centuries. In particular, the Baroque restoration changed completely the features of the church with the insertion of cross vaults, wooden ceiling and stucco decorations (1639-1669): thanks to these measures, that "boxed up" the interior of the building, its solidity was considerably increased.

1703: XI degree of the Mercalli scale.

(4) 4th phase,1703-1915: a quiet period.

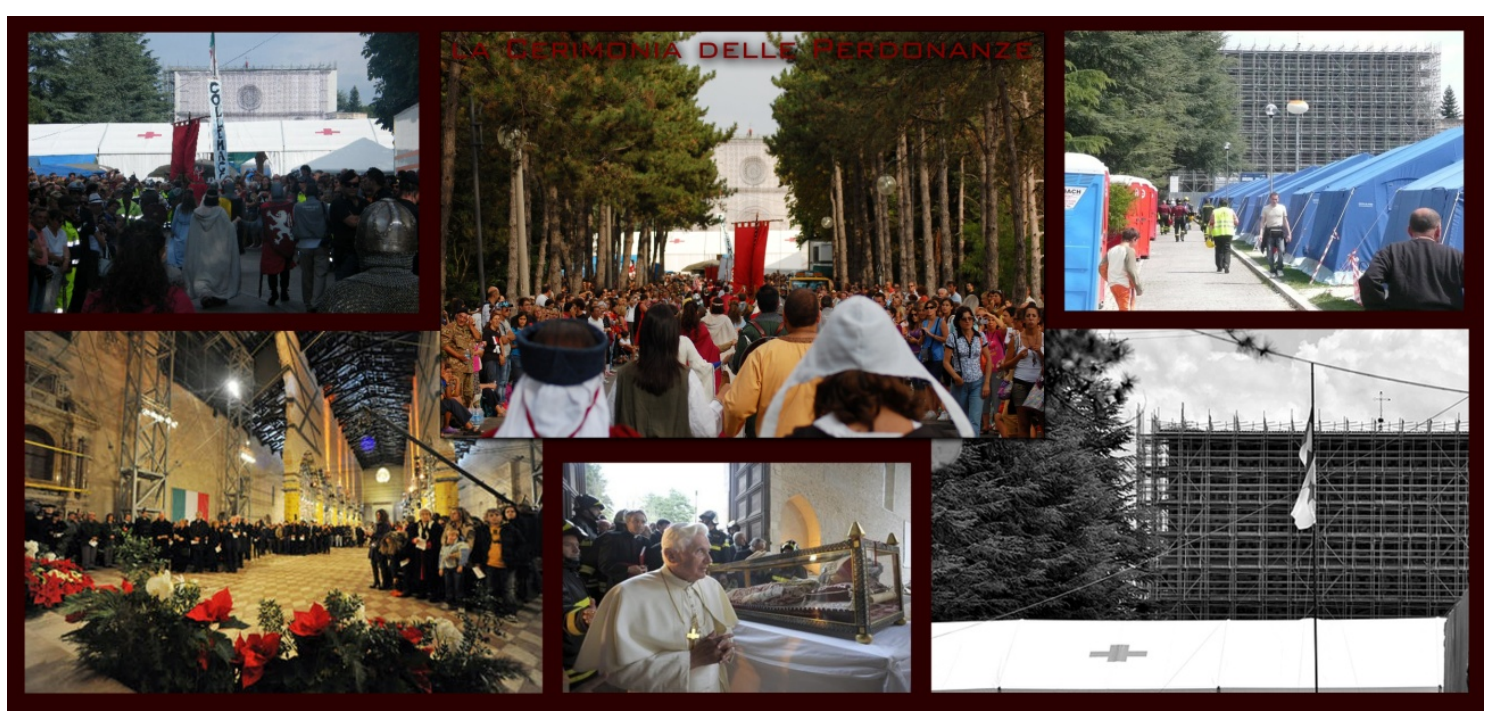

Fig. 2 The way the citizens live their Basilica: the "Perdonanze" Celebration. 


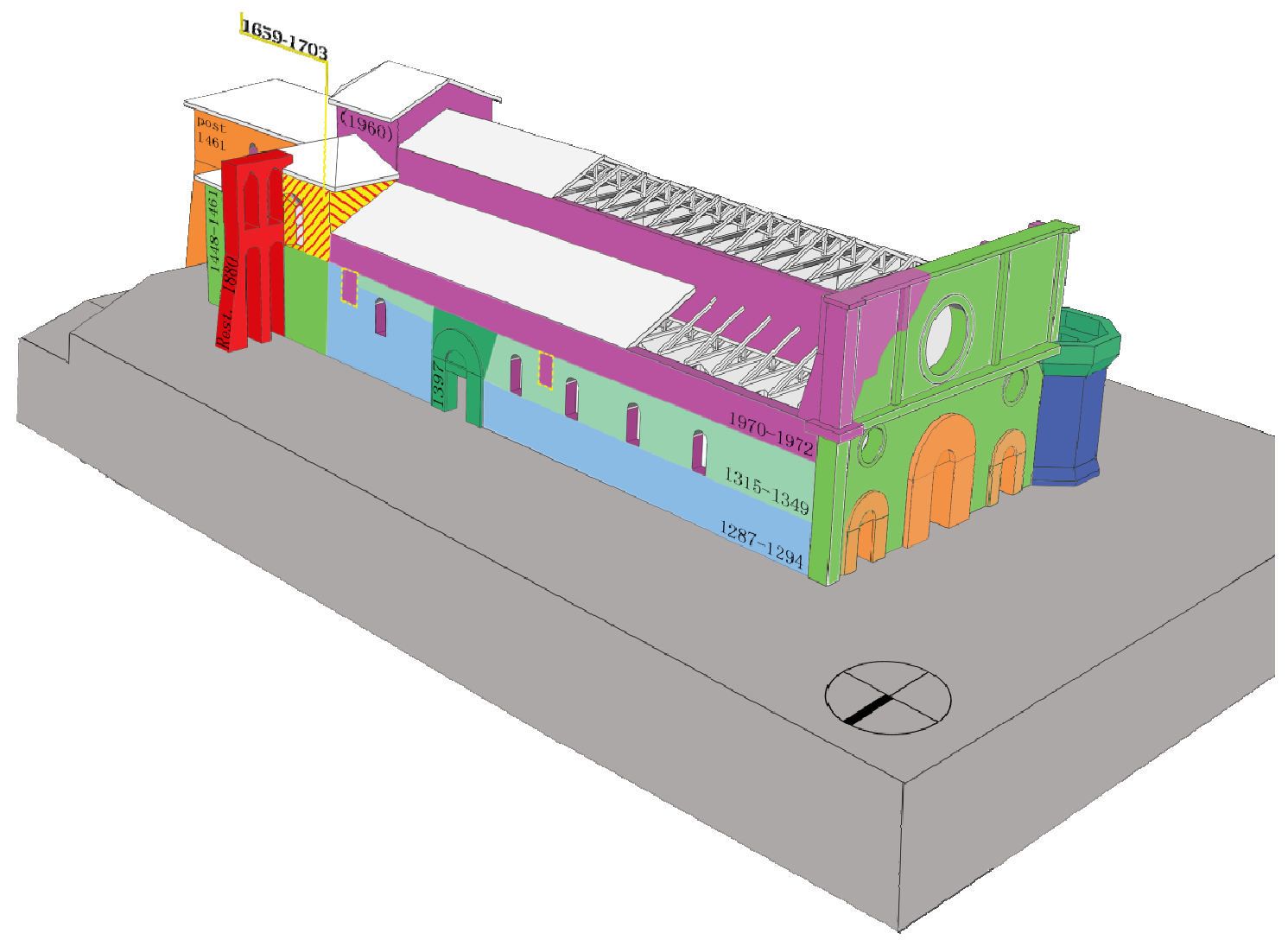

Fig. 3 The model shows the historical evolution of the fabric.

The 19 century was poor of changes: we can attest only a little campaign of restoration interesting the marbles of the façade (1880-1885).

1915: VII-VIII degree of the Mercalli scale.

(5) 5th phase, 1915-2009: the latest restorations.

Indeed, the modifications of 20 century were, in a paradoxical way, the most important of all time, after the 1st World War the left corner of the façade was rebuilt (1920) and it was reinforced by a ferroconcrete frame inserted inside brick buttresses placed in the reverse side of the façade, other buttresses were added in correspondence of the longitudinal wall of the aisles: thanks to this intervention (very invasive but efficacious) the façade did not register huge damages after the last earthquake, because that contributed to anchor it with the main body of the building.

But in the 1960s and the 1970s a lot of different, dangerous measures were adopted.

2009: X degree of the Mercalli scale.

\section{High Risk Interventions: Restorations in the 1960s and the 1970s}

The restoration of these years had the unjustified aim to re-establish the original medieval setting. Mario Moretti was the architect who followed the works. The dome was completely rebuilt in reinforced concrete without any connections with the riddles inserted inside the wall of the central nave, moreover, the walls of the aisles were raised up (almost $3 \mathrm{mt}$ ) putting new riddles at the height of trusses. New windows were opened according to the "medieval style", finally, the cross vaults were abolished as well as the whole baroque decoration, including the wooden ceiling of the nave.

All these interventions are some of the main causes of the huge breakdown of the April 6, 2009.

After the Umbria-Marche earthquake (1997), the Cultural Goods Superintendence considered necessary to adopt new measures to improve the transversal 


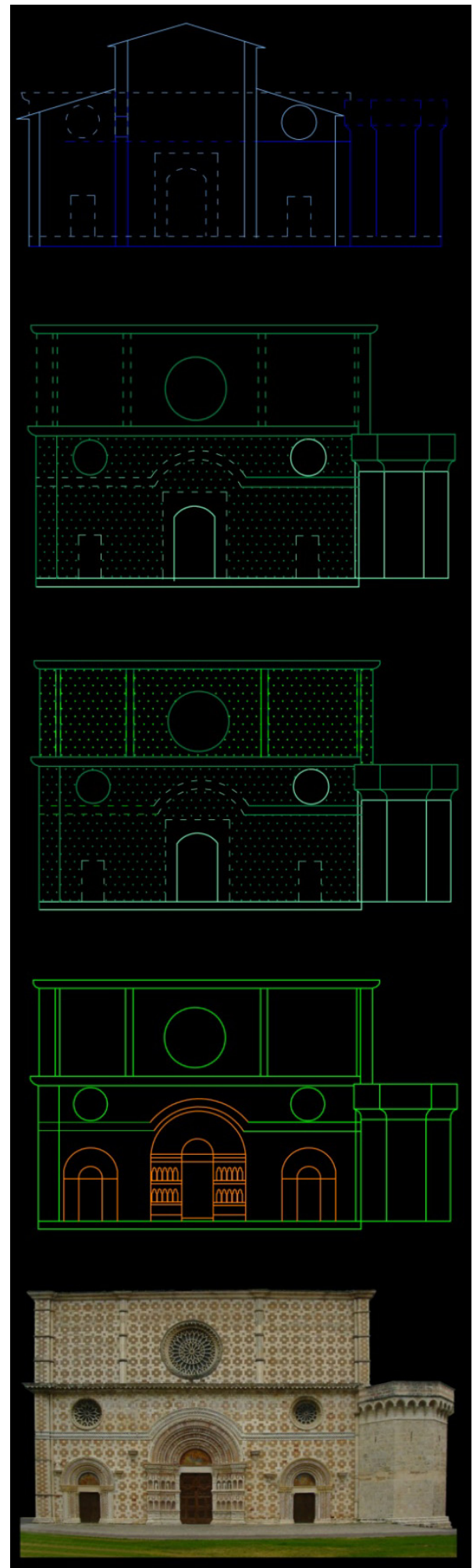

Fig. 4 The constructive phases of the façade.

answer of the Basilica: in fact after Moretti's interventions, the aisles proved to be the most vulnerable structural parts from the seismic point of view. The main seismic improvements were the reinforcement of the wooden roofing by inserting steel wind bracing elements (St. Andrew crosses) and the reinforcement of the aisle walls by means of mortar injections.

\section{April 6th, 2009: Interior and Exterior Damages}

The most considerable damages, registered on April 6, 2009 (Fig. 5), are mainly imputable to wicked renewal works realized in the 1970s, in particular, the insertion of reinforced concrete structures caused:

- the dome's collapse (Fig. 6);

- the partial tumbling down of the presbytery;

- the collapse of the barrel vaults of the transept;

- the collapse of the two monumental clustered pillars sustaining the dome and of the triumphal arch;

- the collapse of an half of the last span of the nave;

- the collapse of the whole wooden roofing of the transept [3].

So, in practice, the church results divided into two parts: on one hand, the nave and the aisles, on the other hand, the apse [4]. Only the façade is safe, thanks to the reinforced concrete structures introduced in the 1920 s, that contributed to tie it with the building's structure.

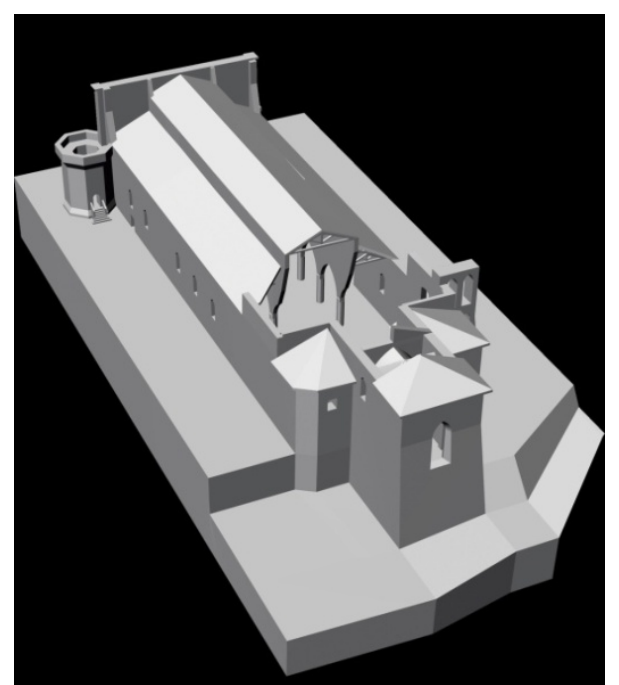

Fig. 5 One of the Rhino models showing the damages of the roofing. 


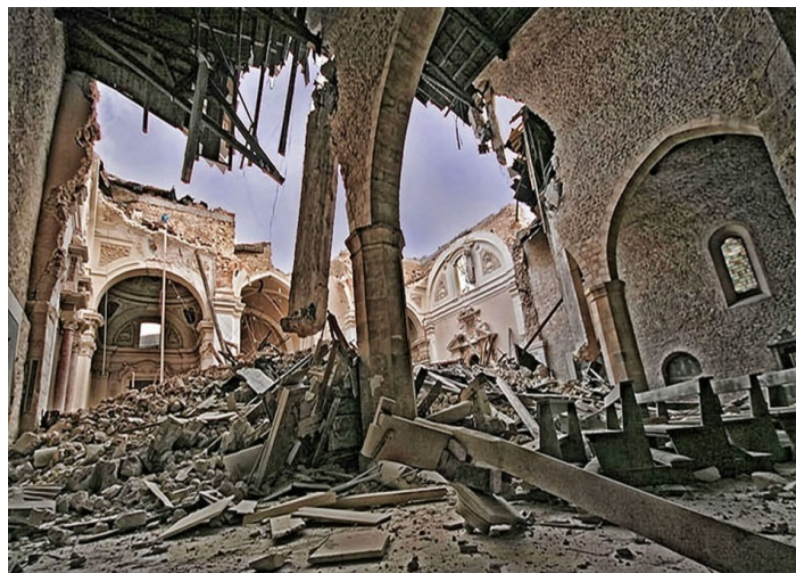

Fig. 6 April 6th, 2009: the collapse of the dome.

There are many other damages of lower gravity such as cracks, lesions, expulsion wedges on the walls and the splitting of the pillars of the nave.

\section{Post-Seism Provisional Measures}

The provisional measures [5] adopted after the last seism, link the employment of traditional technologies with modern ones [6].
The analysis of these methods (their characteristics, localization inside the fabric and effectiveness) allowed to define an interesting and useful abacus of measures [7].

The exterior (Fig. 7): the most used method is the wood propping to contrast above all the expulsion wedges and the steel propping of the openings (above all next to the bell tower and the windows of the apse), as the façade did not register huge damages (it is a sort of "slab" anchored to the main body of the church, and this has strongly strengthen it) in front of it there is only a scaffold to restore little localized damages to the sculptures.

The interior (Fig. 8): the most used method is the steel propping and steel adaptable cradles of the arcades, steel chaines to connect the perimeter walls of the aisles, the installation of a provisional roofing completely realized in steel and plastic materials to cover the portion of the church completely knocked down by the seism.
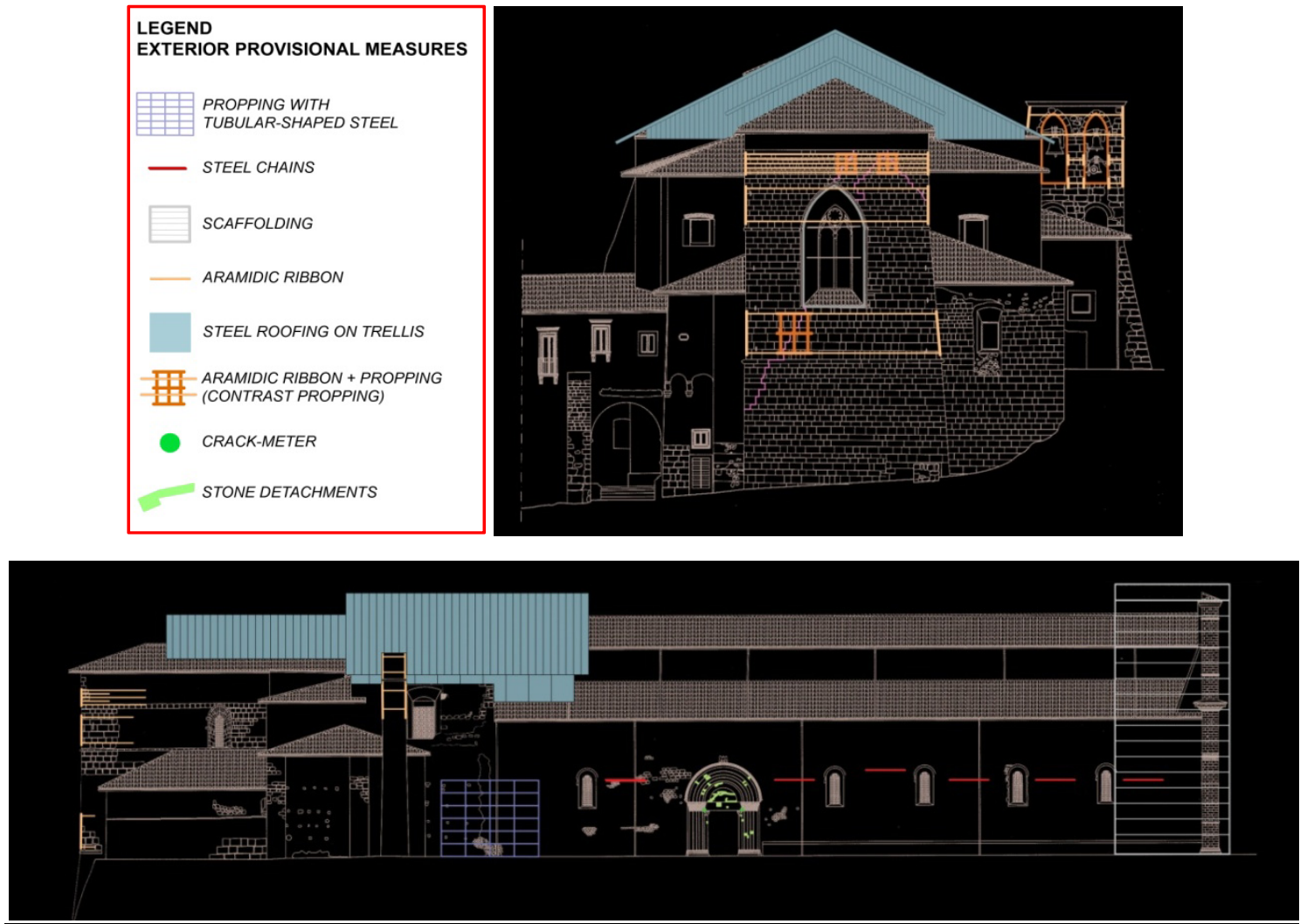

Fig. 7 The survey of the provisional measures on the east and north fronts. 
The interior and exterior interventions employ aramidic fibers and carbon-carbon ribbons alone or with the technologies already mentioned.

To exactly locate these interventions the authors drew up plans, elevations and sections furnished with photos made in situ [8].

\section{Aesthetic-Perceptual Values}

S. Maria di Collemaggio has a lot of aesthetic and perceptive values. It is the most important Romanesque style example in Abruzzi, insomuch as its façade was the prototype of many other buildings of the region.

The collective imagination is hit by the remarkable variety of solutions used in the façade and in the pavement (Fig. 9). The original chromatic texture comes from the combination of two precious and stony local materials, such as rosa brecciato and calcare bianco duro.

The geometries realized, in this way, in the façade find immediate correspondence in the pavement ones, obtained with the same materials. This decoration contributes to animate a façade otherwise too much flat [9].

The sculptures localize the openings: we can find them principally in the three portals and the three rose windows of the façade, and in the Holy Door (Fig. 10).

In this way, these elements of the building assume an evident plastic aspect that produce a contrast with the flat external surfaces of the church.

A very important aspect of this church is the complex geometric conception it hides. The plan is obtained through the reiteration of a unit: the
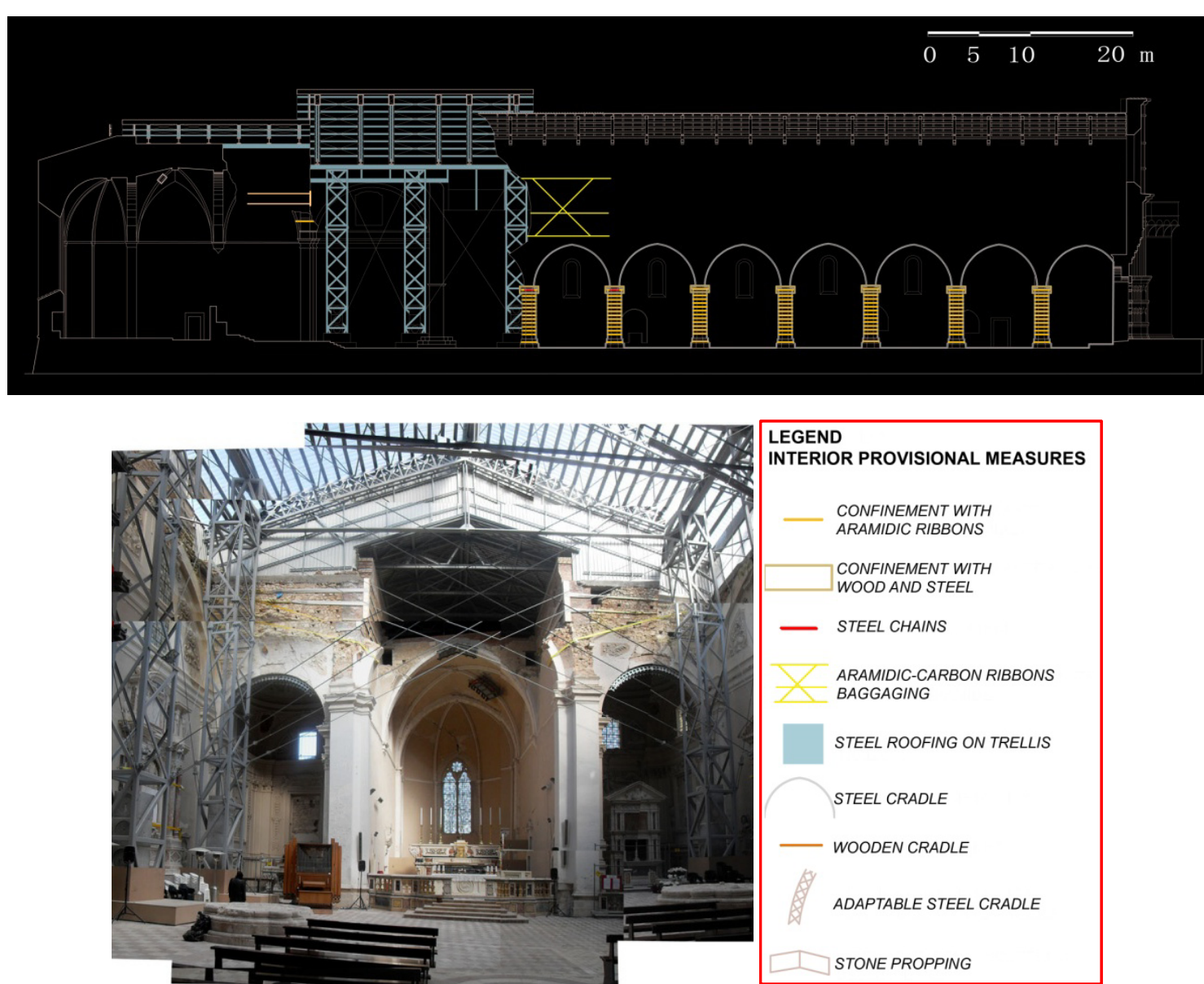

Fig. 8 The survey of the provisional measures on the nave's wall (section) and in the presbytery. 


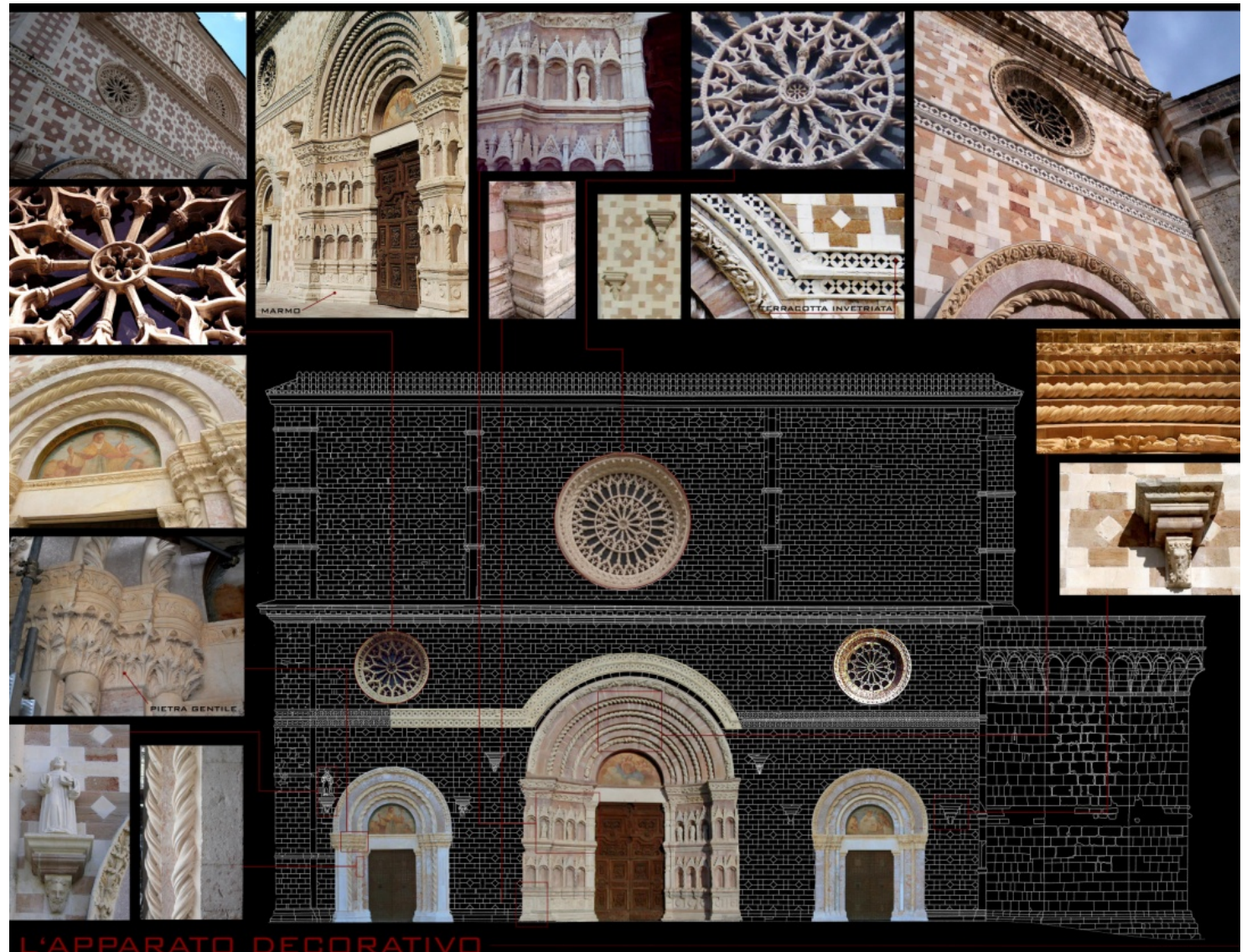

Fig. 9 Façade survey: the decorative system.

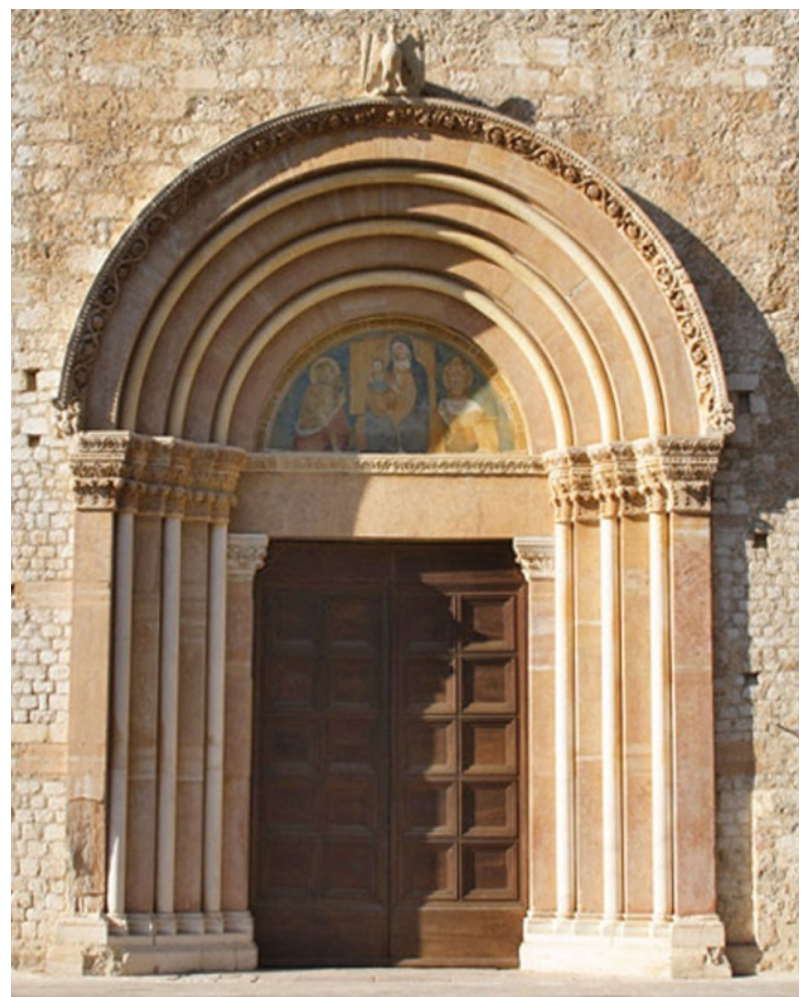

Fig. 10 The Holy Door. 


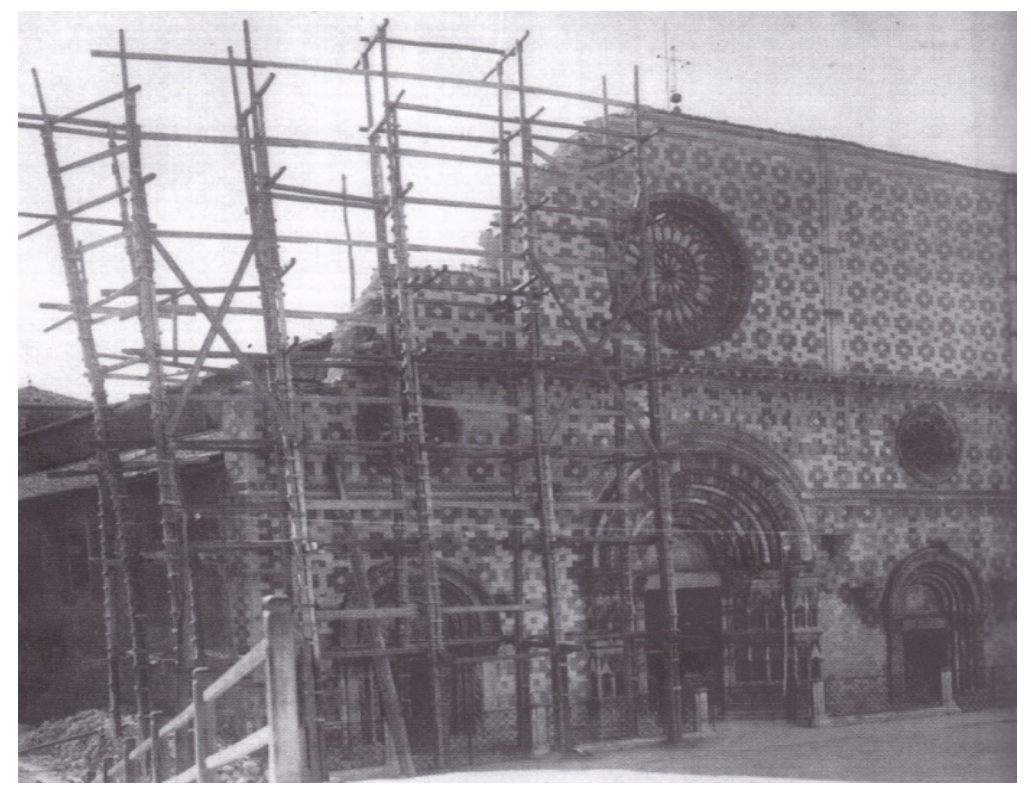

Fig. 11 Restoration of 1920s: disassembly of the left corner of the façade.

longitudinal development is the combination of three circles with a diameter coincident with the width of the façade, measuring ten canne napoletane. Moreover, the façade is realized using the golden section.

\section{Conclusions}

In our mind, the study of all these aspects is crucial for the better preservation of the building, hanging on the future restoration of the good: they are fruit of a precious and accurate analysis of its history and structural evolution, whose knowledge should guide whatever future measure.

In fact with this work, the authors want to highlight how, like in this case, the total or partial destruction of a building is imputable not much to the typology or strength of natural events, but above all to ineffective interventions conducted in the past. The Basilica of Collemaggio allows to compare two different restoring logics, employing the same materials: on one hand the experience of the 1970s begins from an incomplete knowledge of the history and structural characteristics of the building in order to legitimize an age to the detriment of another, and shows, at the same time, the unawareness of its social-historical values; on the other hand, the experience of the 1920s proves that is not much the typology of the materials but their right and well-advised employment that grants the success and the effectiveness of the intervention in the course of time (Fig. 11).

Known the particular situation of today of the Basilica, it is necessary an integration between the "values-system" and the indispensable presence of provisional measures: in spite of the emergency situation, they have to seek primarly to respect the characteristics of the good and their installation has to follow minimal-aggressiveness criterions and considerable reversibility.

The conception and realization of a continuously extendable and updatable abacus of measures, to catalog the surveys of these technologies, has the intent to open the way to an uninterrupted "screening of knowledge", to prevent the atrocious mistakes made in the past.

\section{References}

[1] Seismic Micro-Zoning for the Reconstruction of L'Aquila, Working Group MS-AQ, Department of Civil Protection, Abruzzi Region, L'Aquila, 2010.

[2] C. Bartolomucci, Santa Maria of Collemaggio: Critical Interpretation and Conservation Issue, Palombi \& Partner, Roma, 2004, pp. 37-60.

[3] E. Antonacci, F. Benedettini, F. di Fabio, A. di Egidio, F. Fusco, V. Gattulli, et al., Unit of Earthquake Engineering (UOIS), Basilica of Santa Maria of Collemaggio in 
L'Aquila: Studies and Researches of University, Faculty of Engineering, University of L'Aquila, 2009.

[4] Center for Research Science and Technology for the preservation of Historical and Architectural Heritage (CISTeC), Survey and technical report, University of Rome La Sapienza, Basilica of Santa Maria of Collemaggio, L'Aquila, June 8, 2009.

[5] S. Cecchini, F. Curotti, After-seism rehabilitation interventions in the inner city of L'Aquila: A GIS approach, methodologies and application perspectives, Academic Thesis, 2013.

[6] M. Bellizzi, The Provisional Measures in the Seismic
Emergency, Civil Protection, Rome, 2001.

[7] Services, Documentation and Public Relations of the Fire Department for the Public Aid and the Civil Defence, Vademecum STOP: Technical Specifications of Provisional Measures for the Mass in Post-Earthquake Safety by the Fire Department, Rome, Apr. 2010.

[8] Institute for Construction Technologies, National Research Council, www.jargo.itc.cnr.it (accessed Dec. 5, 2013).

[9] The Ministry of Cultural Heritage and Activities and Tourism Web Site, www.beniculturali.it (accessed Dec. 5, 2013). 